\title{
ADUBAÇÃO FOSFATADA EM VARIEDADES DE CANA-DE-AÇÚCAR CULTIVADAS EM AMBIENTE RESTRITIVO DE CERRADO
}

\author{
Marina Munhoz Rosato Ferreira ${ }^{1}$, Antonio Cesar Bolonhezi ${ }^{2}$, Edson Belisário Teixeira $^{3}$, \\ Cleiton José Queiróz ${ }^{4}$
}

\footnotetext{
${ }^{1}$ Pós-graduando (doutorado) Agronomia, Faculdade de Engenharia de Ilha Solteira / UNESP, Ilha Solteira - SP.

${ }^{2}$ Docente do Departamento de Fitotecnia, Tecnologia de Alimentos e Sócio Economia - Faculdade de Engenharia de Ilha Solteira / UNESP, Ilha Solteira - SP.

${ }^{3}$ Engenheiro Agrônomo na Usina Alcoolvale S/A, Aparecida do Taboado - MS.

${ }^{4}$ Técnico Agrícola na Usina Alcoolvale S/A, Aparecida do Taboado - MS.
}

RESUMO: Com o objetivo de avaliar o desempenho de variedades de cana-de-açúcar a quatro doses de fósforo, aplicados no sulco de plantio, em solo da região de cerrado e em ambiente de produção "D”, foi realizado experimento, safra 2014/15, na Fazenda São José, localizada no município de Aparecida do Taboado (MS). Adotou-se delineamento em blocos casualizados com 16 tratamentos dispostos em esquema fatorial $4 \times 4$ e quatro repetições. Os tratamentos foram constituídos pela combinação de variedades de cana-de-açúcar (CTC 1, CTC 9001, RB835054 e RB965902) e doses de fósforo (0, 150, 300 e $450 \mathrm{~kg} \mathrm{ha}^{-1}$ de $\left.\mathrm{P}_{2} \mathrm{O}_{5}\right)$, utilizando como fonte o superfosfato triplo, aplicado no sulco de plantio da cana planta. As parcelas foram constituídas de cinco linhas de cana-de-açúcar espaçadas de 1,5 m por 10,0 m de comprimento. Foram avaliados o número de perfilhos por metro aos 27, 61, 119, 181 e 265 DAP (dias após plantio), índice de área foliar aos 207 e 362 DAP, teores de nutrientes foliares, características biométricas, produtividade de colmos e agroindustrial e análises tecnológicas. A variedade RB965902 apresentou os menores valores das características que compõem a qualidade da matéria-prima. As doses de fósforo aplicadas no sulco de plantio da cana-deaçúcar, proporcionam aumento linear no índice de área foliar, nos teores foliares de N, P e $\mathrm{Mg}$, porém não influenciam as características agronômicas, produtividade de colmos e agroindustrial e qualidade tecnológica. Ocorre influencia da interação variedades $\mathrm{x}$ doses de $\mathrm{P}$ no teor de P e Mg foliar e Pol\%caldo e Pol\%cana (PC).

Palavras-chave: Saccharum spp. Doses de fósforo. Cana-planta. Manejo.

\section{PHOSPHATE FERTILIZATION IN SUGARCANE VARIETIES CULTIVATED IN STRESSFUL ENVIRONMENT OF CERRADO}

\begin{abstract}
This study aimed to evaluate the performance of sugarcane varieties to four doses of phosphorus fertilizers, applied in the planting furrow, in cerrado soil and in environments of production "D", was conducted this experiment, crop 2014/15, at São José Farm, located in Aparecida do Taboado, Mato Grosso do Sul state, Brazil. The experiment was a randomized blocks design was used in a factorial scheme $4 \mathrm{x} 4$ with 16 treatments consisting by sugarcane varieties (CTC 1, CTC 9001, RB835054 and RB965902) and doses of phosphorus fertilizers $\left(0,150,300\right.$ e $450 \mathrm{~kg} \mathrm{ha}^{-1}$ of $\left.\mathrm{P}_{2} \mathrm{O}_{5}\right)$ applied in the planting furrow, in
\end{abstract}

Cultura Agronômica, Ilha Solteira, v.25, n.3, p.223-240, 2016 
four replications. Using the source of triple superphosphate. The experimental plots were constituted of five rows sugarcane with spacing of 1,5 $\mathrm{m}$ in-between rows by $10 \mathrm{~m}$ long. The variables evaluated were: tillering to $27,61,119,181$ and 265 DAP (days after planting) and leaf area index (LAI) to 207 and 362 DAP, nutrients leaves concentrations, biometrics characteristics, stalk yield and agroindustrial production and technological analyses. The variety RB965902 had the lowest values of the characteristics that make the quality of the raw material. The doses of phosphorus fertilizers applied in the planting furrow provided linear increase in leaf area index, in foliar contents of $\mathrm{N}, \mathrm{P}$ and $\mathrm{Mg}$, but not affect the agronomic characteristics, stalk yield and agroindustrial and technological quality of the sugarcane. Occurs influences the interaction varieties $x$ doses of phosphorus fertilizers the foliar contents of $\mathrm{P}$ and $\mathrm{Mg}$, Pol\%broth and Pol\%sugarcane.

Key words: Saccharum spp. Doses of phosphorus fertilizers. Cane plant. Management.

\section{INTRODUÇÃO}

A cana-de-açúcar (Saccharum spp.) destaca-se como uma das culturas mais importantes do país, sendo o Brasil o maior produtor mundial.

Com as novas áreas de ocupação e o processo produtivo de cana-de-açúcar em solos da região de cerrado, antes ocupados por pastagens, muitas delas degradadas, cujos solos predominantemente são de baixa fertilidade, nesses ambientes de produção denominados restritivos são necessários à adoção de tecnologias para a melhoria das condições químicas do solo e variedades adaptadas para viabilizar e possibilitar a maior longevidade dos canaviais.

O fósforo é o nutriente que mais limita a produtividade e longevidade dos canaviais nessas regiões, por apresentar-se em formas pouco disponíveis as plantas e pelo alto potencial de adsorção. Portanto, a importância da adubação fosfatada na cultura da cana-de-açúcar está em termos de produtividade, qualidade tecnológica e longevidade do canavial. Apesar de ser exigido em menores quantidades pela cana-de-açúcar que o nitrogênio e o potássio, têm-se aplicado quantidades elevadas de fósforo para suprir as necessidades. Deste modo, é importante atentar-se em como aplicar, qual fonte utilizar, quantidades necessárias, localização de nutrientes, de modo a favorecer o desenvolvimento do sistema radicular dos diversos ciclos produtivos.

O fósforo, de acordo com Meyer e Wood (2001), desempenha papel importante na fotossíntese, no desenvolvimento radicular, no perfilhamento e na qualidade do caldo da canade-açúcar para a indústria.

Sabe-se que nas soqueiras, raramente as adubações com fósforo resultam em aumentos na produtividade de colmos. Desta forma, a aplicação da dose adequada de fósforo em canaplanta é importante para o estabelecimento de uma boa população de colmos, o que contribui para a obtenção de soqueiras mais vigorosas.

O elenco de variedades disponíveis para esses ambientes de cerrado, especialmente de baixa altitude, é pequeno e com materiais pobres em sacarose. Desse modo, os programas de

Cultura Agronômica, Ilha Solteira, v.25, n.3, p.223-240, 2016 
melhoramento genético tem a preocupação em buscar genótipos mais modernos e que apresentem boa adaptação nessas condições mais restritivas, com atenção para híbridos com menor sensibilidade ao florescimento, adaptadas a mecanização de plantio e colheita, boa tolerância a déficits hídricos e se possível, mais ricas em sacarose.

Avaliar o desempenho agrotecnológico de novas variedades associadas a uma melhor nutrição da planta pode ser uma alternativa viável técnica e econômica que pode contribuir para a sustentabilidade do setor canavieiro nestes ambientes.

Em pesquisa realizada em Latossolo Vermelho álico de cerrado - ambiente de produção "D", Teixeira (2014) mencionou que a fosfatagem proporcionou incremento na porcentagem de sacarose nas variedades de maturação precoce de cana-de-açúcar e que as variedades respondem de modo diferente à adubação fosfatada corretiva, portanto deve ser considerada no planejamento varietal.

O fósforo pode ser uma alternativa técnica para a obtenção de maiores produtividades e maiores teores de sacarose nestes ambientes restritivos. Portanto, o presente estudo, teve como objetivo avaliar o desempenho de variedades de cana-de-açúcar a doses de fósforo, aplicados no sulco de plantio, em um solo da região de cerrado - ambiente de produção " $\mathrm{D}$ ".

\section{MATERIAL E MÉTODOS}

O experimento foi desenvolvido no período de março de 2014 a abril de 2015 na Fazenda São José, 20¹7’03” S, 51¹9’02” W e 366 m de altitude, em área administrada pela Usina Alcoolvale S/A, no município de Aparecida do Taboado (MS).

O clima é tipo Aw pela classificação de Köppen, temperatura média anual é de $23,5^{\circ} \mathrm{C}$, a precipitação pluvial média anual é de $1370 \mathrm{~mm}$ e a umidade relativa do ar média anual entre 70 e $80 \%$.

O solo da área experimental é classificado como Latossolo Vermelho álico de textura argilosa (DEMATTÊ, 2007) e ambiente de produção "D".

Os valores de precipitação pluvial $(\mathrm{mm})$ durante o ciclo da cultura podem ser observados na Figura 1. Durante o ciclo da cana-planta a precipitação pluvial total foi de $1715,50 \mathrm{~mm}$.

Antes da instalação do experimento foram realizadas amostragens do solo da área na camada de 0,0 a 0,25m e de 0,25 a $0,50 \mathrm{~m}$ para análise química, conforme metodologia proposta por Raij et al. (2001) (Tabela 1).

Cultura Agronômica, Ilha Solteira, v.25, n.3, p.223-240, 2016 


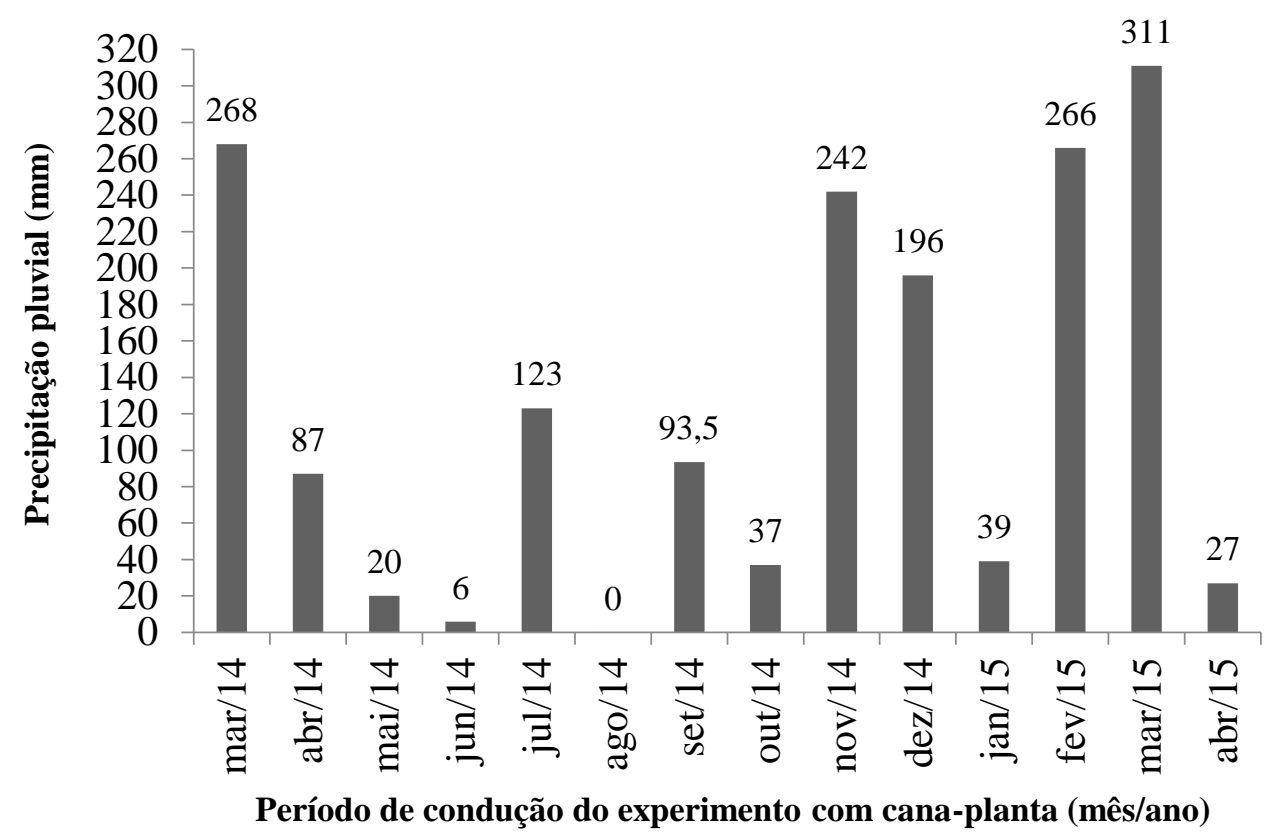

Figura 1. Precipitação pluvial registrada durante a condução do experimento. Aparecida do Taboado (MS), 2014 e 2015.

Tabela 1. Resultado na análise química do solo, amostrado antes da instalação do experimento. Aparecida do Taboado (MS), 2014.

\begin{tabular}{|c|c|c|c|c|c|c|c|c|c|c|}
\hline \multirow{2}{*}{$\begin{array}{l}\text { Prof. } \\
\text { (m) }\end{array}$} & $P$ resina & M.O. & pH & $\mathbf{K}$ & $\mathbf{C a}$ & Mg & H+Al & Al & CTC & \multirow{2}{*}{$\frac{\mathbf{V}}{(\%)}$} \\
\hline & $\mathrm{mg} \mathrm{dm^{-3 }}$ & $\mathrm{g} \mathrm{dm}^{-3}$ & $\left(\mathrm{CaCl}_{2}\right)$ & ---- & -----. & $\mathrm{mmol}$ & $\mathrm{dm}^{-3}$ &  & ----- & \\
\hline $0-0,25$ & 5 & 18 & 4,6 & 0,54 & 13,56 & 8,5 & 26 & 1,85 & 48,6 & 46,5 \\
\hline $0,25-0,50$ & 4 & 14 & 4,7 & 0,27 & 7,28 & 5,66 & 26 & 3,00 & 39,2 & 33,7 \\
\hline
\end{tabular}

A cultura foi instalada em área de reforma do canavial. O preparo do solo constituiu de dessecação da soqueira da cana com glifosato $\left(2,4 \mathrm{~kg}\right.$ do i.a. ha $\left.{ }^{-1}\right)$, grade pesada, aplicação de $1 \mathrm{t} \mathrm{ha}{ }^{-1}$ de calcário e $1 \mathrm{t} \mathrm{ha}^{-1}$ de gesso, grade intermediária, aração e nivelamento do solo (2x).

O delineamento experimental utilizado foi o de blocos casualizados com 16 tratamentos dispostos em esquema fatorial $4 \times 4$ e quatro repetições. Os tratamentos foram constituídos pela combinação de variedades precoces de cana-de-açúcar: CTC 1, CTC 9001, RB835054 e RB965902 e doses de fósforo: 0, 150, 300 e $450 \mathrm{~kg} \mathrm{ha}^{-1} \mathrm{de}_{2} \mathrm{O}_{5}$ aplicados no sulco de plantio da cana planta.

As unidades experimentais foram constituídas de cinco linhas de cana-de-açúcar espaçadas de $1,5 \mathrm{~m}$ e $10,0 \mathrm{~m}$ de comprimento, totalizando $75 \mathrm{~m}^{2}$ cada parcela, sendo considerada como parcela útil para as avaliações as 3 linhas centrais.

A aplicação do fósforo foi realizada no dia do plantio, no fundo do sulco de plantio, antes da distribuição das mudas de cana-de-açúcar. A fonte utilizada de fósforo foi o superfosfato triplo (46\% de $\mathrm{P}_{2} \mathrm{O}_{5}$ total, $41 \%$ de $\mathrm{P}_{2} \mathrm{O}_{5}$ solúvel em água e $12 \% \mathrm{Ca}$ ). 
A sulcação mecânica foi realizada a $0,40 \mathrm{~m}$ de profundidade e a adubação utilizada no sulco de plantio foi de $680 \mathrm{~kg} \mathrm{ha}^{-1}$ da fórmula 20-00-20, variando apenas as doses de $\mathrm{P}_{2} \mathrm{O}_{5}$ segundo o delineamento experimental.

O plantio foi realizado no dia 17 de abril de 2014 com mudas de 11 meses de idade, colocando-se 12 gemas viáveis por metro de sulco. A cobertura dos toletes foi realizada mecanicamente e, concomitante a esta operação foram aplicados os inseticidas fipronil (200 g i.a. ha $\left.{ }^{-1}\right)$ e carbofurano (1.750 g i.a. ha $\left.{ }^{-1}\right)$.

O controle de plantas daninhas foi realizado com aplicação dos herbicidas: diuron + hexazinona (889,2 $\mathrm{g} \mathrm{ha}^{-1}$ do i.a. $+250,8 \mathrm{~g} \mathrm{ha}^{-1}$ do i.a.); Clomazona (960 $\mathrm{g} \mathrm{ha}^{-1}$ do i.a.); MSMA (948 $\mathrm{g} \mathrm{ha}^{-1}$ do i.a.); Sulfentrazona (300 $\mathrm{g} \mathrm{ha}^{-1}$ do i.a.); 2,4 D (402 $\mathrm{g} \mathrm{ha}^{-1}$ do i.a.); adjuvante fortmex $\left(0,125 \mathrm{~L} \mathrm{ha}^{-1}\right.$ do p.c.).

Em 25/11/14 foi realizada liberação de cotésia (Cotesia flavipes) na área experimental, 12 copos ha- ${ }^{-1}$ (18.000 adultos de $C$. flavipes por hectare), visando o controle da broca da cana (Diatraea saccharalis).

O corte da cana-planta (362 DAP) foi realizado manualmente sem a queima da palha, no dia 14 de abril de 2015.

Foram avaliados o número de perfilhos por metro, aos 27, 61, 119, 181 e 265 DAP (dias após plantio), onde foram contados todos os perfilhos na área útil da parcela. Os dados foram convertidos para número de perfilhos por metro. O índice de área foliar (IAF), aos 207 DAP e 362 DAP, em 10 plantas nas três linhas centrais de cada parcela (área útil). Sendo que o índice de área foliar (IAF) foi determinado pela equação

\section{NPI x AF/S}

em que: NPI corresponde ao número de perfilhos $\left(\mathrm{m}^{2}\right)$; AF é a área foliar por perfilho $\left(\mathrm{m}^{2}\right)$; e $\mathrm{S}$ é a área do terreno, em $\mathrm{m}^{2}$, utilizada para a avaliação.

A área foliar por perfilho (AF) foi determinada por meio da contagem do número de folhas verdes (folha totalmente expandida com o mínimo de $20 \%$ de área verde, contada a partir da folha +1 ) e pelas medições nas folhas +3 , sendo obtidos o comprimento e a largura da folha na porção mediana, segundo metodologia descrita por Hermann e Câmara (1999), utilizando a equação

$$
\mathrm{AF}=\mathrm{C} \times \mathrm{L} \times 0,75 \times(\mathrm{N}+2)
$$

em que $\mathrm{C}$ é o comprimento da folha +3 , L é a largura da folha $+3,0,75$ é o fator de correção para área foliar da cultura, e $\mathrm{N}$ é o número de folhas abertas com pelo menos $20 \%$ de área verde.

Para avaliação dos teores de nutrientes foliares foram coletadas as folhas +1 de 15 plantas, da área útil de cada parcela, retirando os $20 \mathrm{~cm}$ centrais da folha +1 (folha mais alta com colarinho visível -“TVP”), excluindo-se a nervura central, segundo a metodologia descrita por Raij e Cantarella (1997), aos 269 DAP (12/01/2015). Posteriormente, as amostras foram acondicionadas em sacos de papel, devidamente identificadas e levadas ao laboratório, onde foram submetidas à secagem em estufa de ventilação forçada à temperatura média de

Cultura Agronômica, Ilha Solteira, v.25, n.3, p.223-240, 2016 
$65^{\circ} \mathrm{C}$, por cerca de 72 horas. Após a secagem, as folhas coletadas foram moídas em moinho tipo Wiley, em seguida efetuadas as digestões das amostras (sulfúrica para N; nitroperclórica para $\mathrm{P}, \mathrm{K}, \mathrm{Ca}, \mathrm{Mg}$ e S), para determinação dos teores de macronutrientes ( $\mathrm{N}, \mathrm{P}, \mathrm{K}, \mathrm{Ca}, \mathrm{Mg}$ e S), conforme descrito em Malavolta et al. (1997).

Por ocasião da colheita, foram realizadas análises de biometria da cultura, onde foram tomados, 45 colmos de cana, nas três linhas centrais de cada parcela, sendo, 3 pontos de 15 colmos consecutivos em cada ponto, amostragem em diagonal, avaliando-se comprimento de colmos, com auxílio de uma trena, foi determinado pela medição da distância de sua base, rente ao solo, até a inserção do palmito; diâmetro médio de colmos, obtido pela média da medição do diâmetro da base, meio e ponta, com auxílio de um paquímetro; massa de um colmo, medidos em balança e posteriormente calculados a massa média de um colmo.

Para a avaliação da produtividade de colmos e produtividade agroindustrial, foram coletados 45 colmos nas três linhas centrais de cada parcela, sendo, 3 pontos de 15 colmos consecutivos em cada ponto, amostragem em diagonal, de acordo com a metodologia descrita por Gheller et al. (1999). Para obter a massa dos 45 colmos foi utilizada uma balança do tipo dinamômetro com precisão de $0,05 \mathrm{~kg}$, determinando-se então a massa média de um colmo dividindo-se a massa encontrada por 45. De posse da massa média de um colmo, do número médio de colmos industrializáveis por metro de linha e do espaçamento entre sulcos, foi possível determinar a produtividade de colmos por hectare (TCH). A produtividade agroindustrial da cana-de-açúcar ( $\mathrm{t} \mathrm{ha}{ }^{-1}$ de Pol) foi obtida através da multiplicação da produtividade de colmos com a porcentagem de Pol\%cana (PC).

Dos 45 colmos utilizados para cálculo da produtividade, foram retirados 10 colmos para as análises tecnológicas. As amostras, devidamente identificadas, foram enviadas ao laboratório de pagamento da cana pelo teor de sacarose (PCTS) da Usina Alcoolvale S/A, para determinação de Brix\%caldo, Pol\%caldo, Pureza (\%), AR\%caldo (açúcares redutores do caldo), PC (Pol\%cana), AR\%cana (açúcares redutores da cana), Fibra\%cana e cálculo da quantidade de ATR por hectare (açúcar total recuperável - ATR em kg de açúcar t ${ }^{-1}$ de cana), conforme métodos definidos pelo CONSECANA (2003).

Os resultados foram submetidos ao teste $\mathrm{F}$ de análise de variância, sendo as médias das variedades comparadas pelo teste de Tukey a 5\% de probabilidade e as médias de doses pela análise de regressão. Foi utilizado o programa SISVAR - Sistema de Análise de Variância (FERREIRA, 2000).

\section{RESULTADOS E DISCUSSÃO}

O número de perfilhos por metro foi diferente entre as variedades em todas as avaliações realizadas (Tabela 2), pois trata-se de uma característica genética. As variedades tiveram aumento crescente no perfilhamento até aos 181 dias após plantio (DAP) e a partir daí houve uma redução natural no número de perfilhos por metro. Possivelmente pela não sobrevivência dos perfilhos mais novos, em função do desenvolvimento dos perfilhos mais velhos (primeiros perfilhos) que vão se desenvolvendo e ocupando espaço e suas folhas sombreando 
aqueles que brotaram depois, estes não conseguem competir principalmente por luz por serem menos eficientes e morrem.

Esse aumento no perfilhamento até os 180 dias após o plantio da cana-de-açúcar varia em função das condições de temperatura e disponibilidade hídrica favorável e a posterior redução de cerca de 50\% no número de perfilhos, seguida de estabilização a partir dos 270 dias após plantio, tanto em cana-planta quanto em cana-soca (CASTRO; CHRISTOFOLETTI, 2005; SILVA et al., 2002; DAROS et al., 1999; BARBIERI, 1993; PRADO, 1988; DILLEWIJN, 1952).

A variedade CTC 9001 se destacou das demais até os 61 DAP e aos 119 DAP apenas da CTC 1, apresentando o maior número de perfilhos por metro, a partir daí, não perfilhou com tanta intensidade e foi a variedade com menor número de perfilhos por metro (Tabela 2). Sendo destaques as variedades RB835054 e RB965902 aos 119, 181 e 265 DAP, que tiveram crescimento mais lento no início, talvez em decorrência das temperaturas mais baixas e menor quantidade de água disponível e posteriormente uma retomada no perfilhamento, com início das primeiras chuvas.

Em relação às doses de fósforo, verificou-se que apenas aos 119 DAP, as doses de fósforo proporcionaram efeito quadrático, onde os dados ajustaram-se a equação $\mathrm{y}=10,376+0,0198 \mathrm{x}-0,000032 \mathrm{x}^{2}$, para o número de perfilhos por metro. Sendo que, a maior quantidade de perfilhos por metro foi obtida na dose de $309,38 \mathrm{~kg} \mathrm{ha}^{-1} \mathrm{de}_{2} \mathrm{O}_{5}$. Na maior dose de fósforo houve aumento no número de perfilhos por metro em $28,92 \%$ comparado à testemunha.

A ausência de efeitos significativos nas demais avaliações para esta variável também foi observada por Moura (2014) em Alagoas, trabalhando com diferentes doses de superfosfato triplo $\left(0,80,120,160\right.$ e $\left.200 \mathrm{~kg} \mathrm{ha}^{-1}\right)$ aplicado no sulco de plantio em cana-deaçúcar na variedade RB92579.

A análise de variância indicou que não houve efeito significativo da interação variedades $\mathrm{x}$ doses de fósforo aplicados no sulco de plantio, para as variáveis estudadas (Tabela 2). Souza (2007), também não observou efeito significativo para as doses (150, 300 e $450 \mathrm{~kg} \mathrm{ha}^{-1}$ de $\mathrm{P}_{2} \mathrm{O}_{5}$ ) e para a interação variedades e doses no número de colmos por metro em cana-planta cultivada em solo de cerrado, trabalhando com doses de fósforo aplicadas a lanço e incorporadas, utilizando como fonte o superfosfato simples.

Para o índice de área foliar (IAF) houve diferenças significativas entre as variedades estudadas, sendo as variedades CTC 1 e RB965902 com os maiores IAF e a variedade RB835054 com os menores valores (Tabela 2). Esse resultado pode ter ocorrido talvez pelo fato da variedade CTC 1 ter produzido menor número de perfilhos nesta fase do ciclo, compensando em maior área foliar por perfilho. Oliveira et al. (2007) citam que, diversas variáveis influenciam o IAF, entre essas, o número de perfilhos, o número de folhas verdes, o tamanho e a largura destas folhas, a eficiência fotossintética delas, além da influência dos genótipos e dos fatores ambientais. Machado et al. (1985) relatam que, um IAF próximo de 4 é suficiente para interceptar $95 \%$ da radiação solar incidente, na cana-de-açúcar.

Cultura Agronômica, Ilha Solteira, v.25, n.3, p.223-240, 2016 
Também houve efeito significativo das doses de fósforo para o índice de área foliar em ambas as épocas amostradas (Tabela 2), proporcionando efeito linear, onde os dados ajustaram-se a equação $y=2,801938+0,000936 x$ e $y=3,1615+0,001191 x$, aos 207 e 362DAP, respectivamente. A dose mais elevada de fósforo aumentou o IAF aos 207 e 362 DAP em 15,7 e 16,4\%, comparado à testemunha, respectivamente. O fósforo aumenta a eficiência do nitrogênio absorvido o qual se une às cadeias carbonadas, incrementando, assim, a formação de novos tecidos, consequentemente, elevando o índice de área foliar (TAIZ; ZEIGER, 2004).

Tabela 2. Número de perfilhos por metro e Índice de área foliar (IAF) de variedades de canade-açúcar em função de doses de fósforo aplicadas no sulco de plantio. Aparecida do Taboado, MS, 2014/2015.

\begin{tabular}{|c|c|c|c|c|c|c|c|}
\hline \multirow{3}{*}{ Tratamentos } & \multicolumn{5}{|c|}{ Perfilhos/colmos por metro } & \multirow{3}{*}{$\begin{array}{c}\text { IAF } \\
207 \\
\text { DAP }\end{array}$} & \multirow{3}{*}{$\begin{array}{c}\text { IAF } \\
362 \\
\text { DAP }\end{array}$} \\
\hline & 27 & 61 & 119 & 181 & 265 & & \\
\hline & DAP & DAP & DAP & DAP & DAP & & \\
\hline \multicolumn{8}{|c|}{ Doses de $\mathrm{P}_{2} \mathrm{O}_{5}\left(\mathrm{~kg} \mathrm{ha}^{-1}\right)$} \\
\hline 0 & 1,58 & 5,15 & $10,13^{(1)}$ & 15,56 & 10,41 & $2,74^{(2)}$ & $3,11^{(3)}$ \\
\hline 150 & 1,69 & 5,69 & 13,37 & 16,62 & 11,11 & 3,01 & 3,38 \\
\hline 300 & 1,71 & 5,3 & 12,72 & 16,76 & 11,30 & 3,12 & 3,61 \\
\hline 450 & 1,59 & 5,34 & 13,06 & 16,5 & 11,47 & 3,17 & 3,62 \\
\hline \multicolumn{8}{|l|}{ Variedades } \\
\hline CTC 1 & $1,09 \mathrm{c}$ & $3,74 \mathrm{c}$ & $8,79 b$ & $15,28 b$ & $10,48 \mathrm{ab}$ & $3,28 \mathrm{a}$ & $3,59 \mathrm{ab}$ \\
\hline RB835054 & $1,42 b c$ & $4,87 b$ & $12,88 \mathrm{a}$ & $17,05 \mathrm{a}$ & $11,70 \mathrm{a}$ & $2,75 \mathrm{c}$ & $3,04 b$ \\
\hline CTC 9001 & $2,41 \mathrm{a}$ & $7,41 \mathrm{a}$ & $13,64 \mathrm{a}$ & $14,64 b$ & $10,42 b$ & $2,81 \mathrm{bc}$ & $3,45 \mathrm{ab}$ \\
\hline RB965902 & $1,64 b$ & $5,47 b$ & $13,96 a$ & $18,48 \mathrm{a}$ & $11,67 \mathrm{ab}$ & $3,21 \mathrm{ab}$ & $3,64 a$ \\
\hline \multicolumn{8}{|c|}{ Teste F - Valores de F } \\
\hline Variedades (V) & $\begin{array}{c}17,58 * \\
*\end{array}$ & $\begin{array}{c}28,52 * \\
*\end{array}$ & $14,17 * *$ & $13,89 * *$ & $4,43 *$ & $5,13 *$ & $3,26^{*}$ \\
\hline $\begin{array}{l}\text { Doses de } \mathrm{P}_{2} \mathrm{O}_{5} \\
(\mathrm{P})\end{array}$ & $0,25 \mathrm{~ns}$ & $0,64 \mathrm{~ns}$ & $5,44 * *$ & $1,36 \mathrm{~ns}$ & $1,89 \mathrm{~ns}$ & $2,57 *$ & $2,59 *$ \\
\hline $\mathrm{V} \times \mathrm{P}$ & $0,50 \mathrm{~ns}$ & $1,50 \mathrm{~ns}$ & $1,23 \mathrm{~ns}$ & $1,56 \mathrm{~ns}$ & $0,87 \mathrm{~ns}$ & $0,59 \mathrm{~ns}$ & $0,83 \mathrm{~ns}$ \\
\hline R.L. & $0,01 \mathrm{~ns}$ & $0,02 \mathrm{~ns}$ & $8,17 * *$ & $1,99 \mathrm{~ns}$ & $4,96^{*}$ & $6,87 *$ & $6,97 *$ \\
\hline R.Q. & $0,72 \mathrm{~ns}$ & $0,74 \mathrm{~ns}$ & $5,18 * *$ & $2,02 \mathrm{~ns}$ & $0,62 \mathrm{~ns}$ & $0,81 \mathrm{~ns}$ & $0,73 \mathrm{~ns}$ \\
\hline D.M.S. (V) & 0,51 & 1,09 & 2,4 & 1,76 & 1,28 & 0,45 & 0,57 \\
\hline Média Geral & 1,64 & 5,37 & 12,32 & 16,36 & 11,07 & 3,012 & 3,43 \\
\hline $\mathrm{CV}(\%)$ & 32,66 & 21,42 & 20,65 & 11,43 & 12,24 & 15,9 & 17,65 \\
\hline
\end{tabular}

**Significativo a $1 \%$ pelo teste $\mathrm{F}$. *Significativo a $5 \%$ pelo teste $\mathrm{F}$. ns= não significativo. D.M.S.= diferença mínima significativa. $\mathrm{CV}=$ coeficiente de variação. Médias seguidas de letra iguais, na coluna, não diferem entre si pelo teste de Tukey, em nível de $5 \%$ de probabilidade. ${ }^{(1)} \mathrm{y}=10,376+0,0198 \mathrm{x}-0,000032 \mathrm{x}^{2}\left(\mathrm{R}^{2}=0,8187\right) .{ }^{(2)} \mathrm{y}=$ $2,801938+0,000936 x\left(R^{2}=0,8918\right) \cdot{ }^{(3)} y=3,1615+0,001191 x\left(R^{2}=0,8956\right)$.

Os teores foliares médios dos macronutrientes da cana-planta (Tabela 3), nitrogênio, fósforo, cálcio e magnésio estão dentro da faixa considerada adequada (18 a $25 \mathrm{~g}$ de $\mathrm{N}, 1,5$ 3,0g de P, 2,0 a 8,0g de Ca e 1,0 a 3,0g de $\mathrm{Mg} \mathrm{kg}^{-1}$ de matéria seca) para a cultura da canade-açúcar, em relação ao descrito por Raij e Cantarella (1997). Entretanto, os teores foliares 
de potássio e enxofre estão abaixo da faixa considerada adequada (10 a 16 g de K e 1,5 a 3,0 $\mathrm{g}$ de $\mathrm{S} \mathrm{kg}^{-1}$ de matéria seca) para esta cultura, em relação ao descrito por Raij e Cantarella (1997).

As variedades de cana-de-açúcar apresentaram diferenças significativas para os teores de nitrogênio, fósforo, potássio, magnésio e enxofre (Tabela 3). A variedade CTC 9001 apresentou teor de nitrogênio e potássio foliar superior à variedade CTC 1 (nitrogênio e potássio) e RB965902 (potássio). Já a variedade RB965902 apresentou teor de fósforo foliar inferior e teor de magnésio foliar superior às demais variedades. E a variedade RB835054, apresentou o menor teor de enxofre foliar em relação à variedade CTC 1 e CTC 9001.

Com relação às doses de fósforo, constatou-se efeito significativo nos teores foliares de $\mathrm{N}$, P e Mg (Tabela 3), influenciando esses teores de forma linear, onde os dados ajustaram-se a equação $\mathrm{y}=21,193375+0,003477 \mathrm{x}, \mathrm{y}=2,104687+0,000542 \mathrm{x}$ e $\mathrm{y}=1,695+0,000383 \mathrm{x}$, respectivamente. A dose mais elevada de fósforo aumentou os teores foliares de $\mathrm{N}, \mathrm{P}$ e $\mathrm{Mg}$ em 8,48, 13 e 12\%, comparado a testemunha, respectivamente.

Tabela 3. Teores de nitrogênio $(\mathrm{N})$, fósforo $(\mathrm{P})$, potássio $(\mathrm{K})$, Cálcio $(\mathrm{Ca})$, Magnésio $(\mathrm{Mg})$ e enxofre $(S)$ nas folhas de variedades de cana-de-açúcar em função de doses de fósforo aplicadas no sulco de plantio. Aparecida do Taboado, MS, 2014/2015.

\begin{tabular}{|c|c|c|c|c|c|c|}
\hline \multirow{2}{*}{ Tratamentos } & $\mathbf{N}$ & $\mathbf{P}$ & $\mathbf{K}$ & $\mathbf{C a}$ & Mg & $\mathbf{S}$ \\
\hline & \multicolumn{6}{|c|}{$\mathrm{g} \mathrm{kg}^{-1}$} \\
\hline \multicolumn{7}{|c|}{ Doses de $\mathrm{P}_{2} \mathrm{O}_{5}\left(\mathrm{~kg} \mathrm{ha}^{-1}\right)$} \\
\hline 0 & $21,46^{(1)}$ & $2,07^{(2)}$ & 7,64 & 2,47 & $1,66^{(3)}$ & 1,26 \\
\hline 150 & 21,71 & 2,26 & 8,15 & 2,40 & 1,82 & 1,30 \\
\hline 300 & 21,46 & 2,24 & 8,44 & 2,37 & 1,79 & 1,33 \\
\hline 450 & 23,28 & 2,34 & 8,20 & 2,46 & 1,86 & 1,35 \\
\hline \multicolumn{7}{|l|}{ Variedades } \\
\hline CTC 1 & $20,72 b$ & $2,22 \mathrm{a}$ & $7,83 b$ & 2,55 & $1,55 b$ & $1,50 \mathrm{a}$ \\
\hline RB835054 & $21,88 \mathrm{ab}$ & $2,34 \mathrm{a}$ & $8,23 \mathrm{ab}$ & 2,28 & $1,59 b$ & $1,09 b$ \\
\hline CTC 9001 & $23,17 \mathrm{a}$ & $2,31 \mathrm{a}$ & $9,64 \mathrm{a}$ & 2,33 & $1,61 b$ & $1,45 \mathrm{a}$ \\
\hline RB965902 & $22,12 \mathrm{ab}$ & $2,04 \mathrm{~b}$ & $6,74 b$ & 2,53 & $2,37 \mathrm{a}$ & $1,23 \mathrm{ab}$ \\
\hline \multicolumn{7}{|c|}{ Teste F - Valores de F } \\
\hline Variedades (V) & $3,81 *$ & $9,12 * *$ & $8,63 * *$ & $0,41 \mathrm{~ns}$ & $60,01 * *$ & $5,32 * *$ \\
\hline Doses de $\mathrm{P}_{2} \mathrm{O}_{5}(\mathrm{P})$ & $2,89 *$ & $7,04 * *$ & $0,69 \mathrm{~ns}$ & $0,05 \mathrm{~ns}$ & $2,86^{*}$ & $0,28 \mathrm{~ns}$ \\
\hline $\mathrm{V} \times \mathrm{P}$ & $1,30 \mathrm{~ns}$ & $2,19 *$ & $1,15 \mathrm{~ns}$ & $1,47 \mathrm{~ns}$ & $2,29 *$ & $0,86 \mathrm{~ns}$ \\
\hline R.L. & $5,11 *$ & $17,02 * *$ & $1,16 \mathrm{~ns}$ & $0,002 \mathrm{~ns}$ & $6,38 *$ & $0,45 \mathrm{~ns}$ \\
\hline R.Q. & $2,30 \mathrm{~ns}$ & $1,04 \mathrm{~ns}$ & $0,88 \mathrm{~ns}$ & $0,14 \mathrm{~ns}$ & $0,74 \mathrm{~ns}$ & $0,14 \mathrm{~ns}$ \\
\hline D.M.S. (V) & 1,95 & 0,17 & 1,54 & 0,80 & 0,19 & 0,31 \\
\hline Média Geral & 21,98 & 2,23 & 8,11 & 2,42 & 1,78 & 1,32 \\
\hline $\mathrm{CV}(\%)$ & 9,39 & 7,91 & 20,1 & 34,78 & 11,43 & 25,13 \\
\hline
\end{tabular}

**Significativo a $1 \%$ pelo teste $\mathrm{F}$. *Significativo a $5 \%$ pelo teste $\mathrm{F} . \mathrm{ns}=$ não significativo. D.M.S.= diferença mínima significativa. $\mathrm{CV}=$ coeficiente de variação. Médias seguidas de letra iguais, na coluna, não diferem entre si pelo teste de Tukey, em nível de $5 \%$ de probabilidade. ${ }^{(1)} \mathrm{y}=21,193375+0,003477 \mathrm{x} \quad\left(\mathrm{R}^{2}=0,5885\right)$. ${ }^{(2)} \mathrm{y}=$ $2,104687+0,000542 x\left(R^{2}=0,8062\right) .{ }^{(3)} y=1,695+0,000383 x\left(R^{2}=0,7438\right)$.

Cultura Agronômica, Ilha Solteira, v.25, n.3, p.223-240, 2016 
Esses resultados condizem com os observados por Pereira et al. (1995), em que a concentração de fósforo nas folhas (variedade BR 70-194) aumentou linearmente em razão dos níveis de fósforo aplicados $\left(0,60,120,180,240\right.$ e $\left.300 \mathrm{~kg} \mathrm{ha}^{-1} \mathrm{de}_{2} \mathrm{O}_{5}\right)$ no solo, na forma de superfosfato triplo, no plantio. E com as observações de Moda (2015) que, quando avaliado as doses $\left(0,90,180,360 \mathrm{~kg} \mathrm{ha}^{-1}\right.$ de $\left.\mathrm{P}_{2} \mathrm{O}_{5}\right)$, os teores de magnésio, cálcio e enxofre foliar da cana-de-açúcar (variedade RB855453) tiveram ajuste quadrático, na avaliação aos 240 DAP, em Latossolo Vermelho Amarelo distrófico.

Cabe ressaltar ainda que os teores de cálcio foliar (Tabela 3) não foram influenciados pelas doses de fósforo e pelas variedades talvez em decorrência da presença de $12 \%$ de Ca no superfosfato triplo e da reserva no solo (Tabela 1).

$\mathrm{Na}$ Tabela 4 consta, o desdobramento da interação variedades x doses de fósforo para $\mathrm{o}$ teor de fósforo foliar. A variedade RB965902 apresentou os menores valores de teor de fósforo foliar (Tabela 4) em relação às variedades RB835054, CTC 1 e CTC 9001, para as doses aplicadas de 0,300 e $450 \mathrm{~kg} \mathrm{ha}^{-1} \mathrm{de}_{2} \mathrm{O}_{5}$, respectivamente. Constatou-se resposta para as doses de fósforo que se ajustou à função linear apenas para as variedades RB965902 (y= $1,8885+0,000682 x)$, CTC $1(y=2,06275+0,000693 x)$ e CTC $9001(y=2,14275+0,000437 x)$ no teor de fósforo foliar.

Tabela 4. Desdobramento da interação variedades x doses de fósforo, da análise de variância referente ao teor de fósforo $\left(\mathrm{g} \mathrm{kg}^{-1}\right)$ foliar da cana-de-açúcar (cana-planta). Aparecida do Taboado - MS, 2014/2015.

\begin{tabular}{cccccccc}
\hline \multirow{2}{*}{ Variedades } & \multicolumn{3}{c}{ Doses de $\mathbf{P}_{\mathbf{2}} \mathrm{O}_{\mathbf{5}}\left(\mathbf{k g ~ h a}^{-\mathbf{1}}\right)$} & \multicolumn{3}{c}{ Valores de F } \\
\cline { 2 - 8 } & $\mathbf{0}$ & $\mathbf{1 5 0}$ & $\mathbf{3 0 0}$ & $\mathbf{4 5 0}$ & doses & R.L & R.Q. \\
\hline CTC 1 & $2,02 \mathrm{ab}$ & 2,15 & $2,44 \mathrm{a}$ & $2,27 \mathrm{ab}$ & ${ }^{(2)} 4,22^{*}$ & $6,97 * *$ & $3,19 \mathrm{~ns}$ \\
RB835054 & $2,32 \mathrm{a}$ & 2,45 & $2,14 \mathrm{ab}$ & $2,45 \mathrm{ab}$ & $2,77 \mathrm{~ns}$ & $0,03 \mathrm{~ns}$ & $1,07 \mathrm{~ns}$ \\
CTC 9001 & $2,13 \mathrm{ab}$ & 2,33 & $2,28 \mathrm{ab}$ & $2,51 \mathrm{a}$ & ${ }^{(3)} 3,29 *$ & $8,01 * *$ & $0,04 \mathrm{~ns}$ \\
RB965902 & $1,80 \mathrm{~b}$ & 2,12 & $2,10 \mathrm{~b}$ & $2,15 \mathrm{~b}$ & ${ }^{(1)} 3,34^{*}$ & $6,74^{*}$ & $2,22 \mathrm{~ns}$ \\
\hline DMS & 0,33 & 0,33 & 0,33 & 0,33 & - & - & - \\
\hline
\end{tabular}

Médias seguidas de letra iguais, na coluna, não diferem entre si pelo teste de Tukey, em nível de 5\% de probabilidade. D.M.S. = diferença mínima significativa. ${ }^{(1)} \mathrm{y}=1,8885+0,000682 \mathrm{x}\left(\mathrm{R}^{2}=0,6719\right) .{ }^{(2)} \mathrm{y}=$ $2,06275+0,000693 x\left(R^{2}=0,5512\right) .{ }^{(3)} y=2,14275+0,000437 x\left(R^{2}=0,8124\right)$.

Na Tabela 5 consta o desdobramento da interação variedades dentro de doses de fósforo para o teor de magnésio foliar. A variedade RB965902 apresentou os maiores valores de magnésio foliar, diferindo das demais variedades dentro de cada dose de fósforo aplicado. Constatou-se resposta para as doses de fósforo que se ajustou a função linear ( $\mathrm{y}=$ $2,1075+0,001175 x$ ) apenas para a variedade RB965902.

Quanto às características biométricas verificou-se que apenas para o comprimento de colmos não houve diferenças significativas entre as variedades de cana-de-açúcar (Tabela 6). Enquanto que, a variedade CTC 1 apresentou o maior diâmetro e massa de 1 colmo, diferindose das demais variedades. 
Tabela 5. Desdobramento da interação variedades x doses de fósforo, da análise de variância referente ao teor de magnésio $\left(\mathrm{g} \mathrm{kg}^{-1}\right)$ foliar da cana-de-açúcar (cana-planta). Aparecida do Taboado - MS, 2014/2015.

\begin{tabular}{cccccccc}
\hline \multirow{2}{*}{ Variedades } & \multicolumn{3}{c}{ Doses de $\mathbf{P}_{2} \mathrm{O}_{5}\left(\mathrm{~kg} \mathrm{ha}^{-\mathbf{1}}\right)$} & \multicolumn{3}{c}{ Valores de F } \\
\cline { 2 - 8 } & $\mathbf{0}$ & $\mathbf{1 5 0}$ & $\mathbf{3 0 0}$ & $\mathbf{4 5 0}$ & doses & R.L & R.Q. \\
\hline CTC 1 & $1,50 \mathrm{~b}$ & $1,55 \mathrm{~b}$ & $1,56 \mathrm{~b}$ & $1,61 \mathrm{~b}$ & $0,21 \mathrm{~ns}$ & $0,59 \mathrm{~ns}$ & $0,00 \mathrm{~ns}$ \\
RB835054 & $1,69 \mathrm{ab}$ & $1,66 \mathrm{~b}$ & $1,51 \mathrm{~b}$ & $1,49 \mathrm{~b}$ & $1,00 \mathrm{~ns}$ & $2,71 \mathrm{~ns}$ & $0,00 \mathrm{~ns}$ \\
CTC 9001 & $1,45 \mathrm{~b}$ & $1,56 \mathrm{~b}$ & $1,71 \mathrm{~b}$ & $1,71 \mathrm{~b}$ & $1,57 \mathrm{~ns}$ & $4,23 \mathrm{~ns}$ & $0,30 \mathrm{~ns}$ \\
RB965902 & $2,00 \mathrm{a}$ & $2,49 \mathrm{a}$ & $2,38 \mathrm{a}$ & $2,63 \mathrm{a}$ & ${ }^{(1)} 6,94 * *$ & $14,98 * *$ & $1,36 \mathrm{~ns}$ \\
\hline DMS & 0,38 & 0,38 & 0,38 & 0,38 & - & - & -
\end{tabular}

Médias seguidas de letra iguais, na coluna, não diferem entre si pelo teste de Tukey, em nível de 5\% de probabilidade. D.M.S. = diferença mínima significativa. ${ }^{(1)} \mathrm{y}=2,1075+0,001175 \mathrm{x}\left(\mathrm{R}^{2}=0,7199\right)$.

Tabela 6. Características biométricas de variedades de cana-de-açúcar em função de doses de fósforo aplicadas no sulco de plantio. Aparecida do Taboado, MS, 2014/2015.

\begin{tabular}{|c|c|c|c|}
\hline Tratamentos & $\begin{array}{l}\text { Comprimento de } \\
\text { colmo }(\mathrm{m})\end{array}$ & $\begin{array}{l}\text { Diâmetro de } \\
\text { colmo }(\mathrm{cm})\end{array}$ & $\begin{array}{l}\text { Massa de } 1 \\
\text { colmo }(\mathrm{kg})\end{array}$ \\
\hline \multicolumn{4}{|c|}{ Doses de $\mathrm{P}_{2} \mathrm{O}_{5}\left(\mathrm{~kg} \mathrm{ha}^{-1}\right)$} \\
\hline 0 & 3,28 & 2,65 & 1,87 \\
\hline 150 & 3,29 & 2,65 & 1,87 \\
\hline 300 & 3,29 & 2,68 & 1,87 \\
\hline 450 & 3,27 & 2,64 & 1,87 \\
\hline \multicolumn{4}{|l|}{ Variedades } \\
\hline CTC 1 & 3,33 & $2,84 \mathrm{a}$ & $2,12 \mathrm{a}$ \\
\hline RB835054 & 3,25 & $2,56 b$ & $1,73 b$ \\
\hline CTC 9001 & 3,24 & $2,59 b$ & $1,84 b$ \\
\hline RB965902 & 3,31 & $2,62 b$ & $1,80 \mathrm{~b}$ \\
\hline \multicolumn{4}{|c|}{ Teste F - Valores de F } \\
\hline Variedades (V) & $1,79 \mathrm{~ns}$ & $12,00 * *$ & $11,24 * *$ \\
\hline Doses de $\mathrm{P}_{2} \mathrm{O}_{5}(\mathrm{P})$ & $0,12 \mathrm{~ns}$ & $0,30 \mathrm{~ns}$ & $0,004 \mathrm{~ns}$ \\
\hline $\mathrm{V} \times \mathrm{P}$ & $1,21 \mathrm{~ns}$ & $0,94 \mathrm{~ns}$ & $0,99 \mathrm{~ns}$ \\
\hline R.L. & $0,05 \mathrm{~ns}$ & $0,00 \mathrm{~ns}$ & $0,00 \mathrm{~ns}$ \\
\hline R.Q. & $0,25 \mathrm{~ns}$ & $0,39 \mathrm{~ns}$ & $0,01 \mathrm{~ns}$ \\
\hline DMS (V) & 0,12 & 0,14 & 0,19 \\
\hline Média Geral & 3,28 & 2,65 & 1,87 \\
\hline $\mathrm{CV}(\%)$ & 3,99 & 5,53 & 10,77 \\
\hline
\end{tabular}

**Significativo a $1 \%$ pelo teste $\mathrm{F}$. *Significativo a $5 \%$ pelo teste $\mathrm{F} . \mathrm{ns}=$ não significativo. D.M.S.= diferença mínima significativa. $\mathrm{CV}=$ coeficiente de variação. Médias seguidas de letra iguais, na coluna, não diferem entre si pelo teste de Tukey, em nível de $5 \%$ de probabilidade.

Não houve efeito significativo das doses de fósforo e da interação doses de fósforo $\mathrm{x}$ variedades para as mesmas variáveis (Tabela 6). O mesmo foi observado por Caione et al. (2011), que não observaram efeito isolado das doses de fósforo $\left(0,50,100,150\right.$ e $200 \mathrm{~kg} \mathrm{ha}^{-}$ ${ }^{1}$ de $\mathrm{P}_{2} \mathrm{O}_{5}$, fonte superfosfato triplo), na adubação de manutenção (aplicação no sulco de 
plantio), para as variáveis diâmetro de colmos e massa de matéria seca, variedade de cana-deaçúcar forrageira IAC86-2480, em Latossolo Vermelho-Amarelo distrófico. Contrário às observações feitas neste experimento, Korndorfer et al. (1998), verificaram que o peso médio dos colmos (variedade RB72-454), tanto da cana-de-ano como da cana-soca aumentaram com a adubação fosfatada (doses 0, 60, 160 e $180 \mathrm{~kg} \mathrm{ha}^{-1}$ de $\mathrm{P}_{2} \mathrm{O}_{5}$ ) aplicada no sulco de plantio, em solo da região de cerrado.

As variedades apresentaram diferenças significativas apenas para produtividade de pol por hectare (TPH), verificando-se maior produtividade de pol para a variedade CTC 1 (Tabela 7). Tal resultado pode estar relacionado com os maiores valores de diâmetro e massa de 1 colmo (Tabela 6) e PC (Tabela 8) para esta variedade, influenciando portanto a TPH.

Não houve efeito significativo das doses de fósforo e da interação doses de fósforo $\mathrm{x}$ variedades (Tabela 7) para produtividade de colmos (TCH) e produtividade agroindustrial (TPH). Em contrapartida, Simões Neto et al. (2012) reportaram que, a adubação fosfatada em diferentes solos nas condições de cana-planta influenciou positivamente a produção agrícola (TCH) e industrial (TPH), na Zona da Mata do Estado de Pernambuco, de duas variedades de cana-de-açúcar (RB863129 e RB855536). Assim como Korndorfer et al. (1998) que, notaram efeito da adubação fosfatada (doses 0, 60, 160 e $180 \mathrm{~kg} \mathrm{ha}^{-1}$ de $\mathrm{P}_{2} \mathrm{O}_{5}$ ) aplicada no sulco de plantio, em solo da região de cerrado, sobre a produtividade da cana, sendo linear e positiva na cana-planta e na cana-soca, variedade RB72-454.

Costa et al. (2014) avaliando a produtividade de cana-de-açúcar (variedade RB 92579) em Argissolo do nordeste de diferentes texturas em resposta a adubação fosfatada $(0 ; 40 ; 80$; $120 ; 160$ e $200 \mathrm{~kg} \mathrm{ha}^{-1}$ de $\mathrm{P}_{2} \mathrm{O}_{5}$ aplicadas no fundo do sulco de plantio, fonte superfosfato triplo) encontraram efeito significativo e ajuste de modelo quadrático, sendo que as doses de máxima eficiência agronômica foram de $107 \mathrm{~kg} \mathrm{ha}^{-1}$ no Argissolo Amarelo Distrocoeso de textura média, $120 \mathrm{~kg} \mathrm{ha}^{-1}$ no Argissolo Vermelho Amarelo distrófico de textura argilosa e $130 \mathrm{~kg} \mathrm{ha}^{-1}$ no Argissolo Vermelho Amarelo distrófico de textura arenosa.

Santos et al. (2011) notaram que as doses de $100 \mathrm{~kg} \mathrm{ha}^{-1}$ e $200 \mathrm{~kg} \mathrm{ha}^{-1}$ de $\mathrm{P}_{2} \mathrm{O}_{5}$ (fonte superfosfato triplo) resultaram em maior TPH, superando as demais. Obtendo ganhos em produtividade de açúcar (variedade RB867515) de 30,7\% e 33,3\%, respectivamente, quando comparados com a testemunha.

Embora não havendo efeito significativo entre as doses de fósforo para a variável produtividade agroindustrial (Tabela 7), deve-se ressaltar ganho de 1,7 toneladas de pol ha-1 $(10,6 \%)$ na maior dose comparada a testemunha, influenciado pela maior produtividade de cana $(\mathrm{TCH})$. Esse ganho é expressivo para o início de safra, indicando a necessidade da continuidade das pesquisas para melhor avaliar a nutrição de fósforo e sua importância na qualidade tecnológica das canas precoces.

O regime pluviométrico no ciclo da cultura (Figura 1) foi bastante favorável ao desenvolvimento da cana, contribuindo positivamente para os bons resultados obtidos em toneladas de cana por hectare (Tabela 7).

Cultura Agronômica, Ilha Solteira, v.25, n.3, p.223-240, 2016 
Tabela 7. Produtividade de colmos (TCH) e Produtividade agroindustrial (TPH) de cana-deaçúcar em função de doses de fósforo aplicadas no sulco de plantio. Aparecida do Taboado, MS, 2014/2015.

\begin{tabular}{|c|c|c|}
\hline \multirow{2}{*}{ Tratamentos } & TCH & TPH \\
\hline & Toneladas de cana ha ${ }^{-1}$ & Toneladas de Pol ha ${ }^{-1}$ \\
\hline \multicolumn{3}{|c|}{$\overline{D o s e s ~ d e ~} \mathrm{P}_{2} \mathrm{O}_{5}\left(\mathrm{~kg} \mathrm{ha}^{-1}\right)$} \\
\hline 0 & 129,30 & 16,07 \\
\hline 150 & 137,14 & 16,50 \\
\hline 300 & 140,93 & 17,34 \\
\hline 450 & 142,78 & 17,77 \\
\hline \multicolumn{3}{|l|}{ Variedades } \\
\hline CTC 1 & 148,08 & $18,75 \mathrm{a}$ \\
\hline RB835054 & 135,10 & $17,02 \mathrm{ab}$ \\
\hline СТC 9001 & 127,29 & $15,51 b$ \\
\hline RB965902 & 139,67 & $16,39 \mathrm{ab}$ \\
\hline \multicolumn{3}{|c|}{ Teste F - Valores de F } \\
\hline Variedades (V) & $2,15 \mathrm{~ns}$ & $3,31 *$ \\
\hline Doses de $\mathrm{P}_{2} \mathrm{O}_{5}(\mathrm{P})$ & $1,01 \mathrm{~ns}$ & $1,06 \mathrm{~ns}$ \\
\hline $\mathrm{V} \times \mathrm{P}$ & $0,45 \mathrm{~ns}$ & $0,72 \mathrm{~ns}$ \\
\hline R.L. & $2,78 \mathrm{~ns}$ & $3,12 \mathrm{~ns}$ \\
\hline R.Q. & $0,26 \mathrm{~ns}$ & $0,00 \mathrm{~ns}$ \\
\hline D.M.S. (V) & 22,39 & 2,84 \\
\hline Média Geral & 137,53 & 16,92 \\
\hline $\mathrm{CV}(\%)$ & 17,26 & 17,78 \\
\hline
\end{tabular}

**Significativo a $1 \%$ pelo teste $\mathrm{F} . *$ Significativo a $5 \%$ pelo teste $\mathrm{F} . \mathrm{ns}=$ não significativo. D.M.S.= diferença mínima significativa. $\mathrm{CV}=$ coeficiente de variação. Médias seguidas de letra iguais, na coluna, não diferem entre si pelo teste de Tukey, em nível de 5\% de probabilidade.

Das características que compõem a qualidade tecnológica da cana, verifica-se que houve diferenças apenas entre as variedades em todas as variáveis analisadas, com destaque para a variedade CTC 1 com a maior média e a variedade RB965902 com a menor média (Tabela 8).

Nenhuma das características tecnológicas avaliadas foi influenciada pelas doses de fósforo (Tabela 8). Resultados semelhantes obtiveram Simões Neto et al. (2012) que, avaliando a aplicação de doses de fósforo aplicados no sulco de plantio (superfosfato triplo) de acordo com os tipos de solo na Zona da Mata do Estado de Pernambuco, verificaram que as doses de fósforo não influenciaram as características industriais das variedades RB863129 e RB855536. Korndorfer et al. (1998), também notaram que a concentração de Pol da cana (variedade RB72-454) não foi afetada pela adubação fosfatada (doses 0, 60, 160 e $180 \mathrm{~kg} \mathrm{ha}{ }^{-}$ ${ }^{1}$ de $\mathrm{P}_{2} \mathrm{O}_{5}$ ) aplicada no sulco de plantio, em solo da região de cerrado.

Resultados similares foram observados por Pereira et al. (1995), em experimento instalado em um Vertissolo com a variedade de cana-de-açúcar BR 70-194, em que a pol (\%)

Cultura Agronômica, Ilha Solteira, v.25, n.3, p.223-240, 2016 
do caldo da cana não variou com os níveis crescentes de fósforo $(0,60,120,180,240$ e 300 $\mathrm{kg} \mathrm{ha}^{-1}$ de $\mathrm{P}_{2} \mathrm{O}_{5}$ ) aplicados no solo, na forma de superfosfato triplo, no plantio.

No entanto, Santos et al. (2011) constataram que as doses de fósforo (50, 100 e $200 \mathrm{~kg}$ $\mathrm{ha}^{-1}$ de $\mathrm{P}_{2} \mathrm{O}_{5}$, fonte superfosfato triplo), aplicadas no sulco de plantio, influenciaram positivamente as variáveis tecnológicas ${ }^{\circ}$ Brix, Pureza do caldo e TPH da variedade RB867515.

Em contrapartida, houve efeito significativo da interação doses de fósforo $\mathrm{x}$ variedades (Tabela 8) para as variáveis Pol\%caldo e Pol\%cana.

Tabela 8. Análises tecnológicas ((Brix\%caldo, Pol\%caldo, Pureza (\%), AR\%caldo, PC (Pol\%cana), AR\%cana, Fibra\%cana) e ATR (kg de açúcar $\mathrm{t}^{-1}$ de cana)) de variedades de canade-açúcar em função de doses de fósforo aplicadas no sulco de plantio. Aparecida do Taboado, MS, 2014/2015.

\begin{tabular}{lcccccccc}
\hline \multicolumn{1}{c}{ Tratamentos } & Brix & Pol & Pureza & AR caldo & PC & AR cana & Fibra & ATR \\
\hline Doses de $\boldsymbol{P}_{2} \boldsymbol{O}_{5}\left(\boldsymbol{k g} \boldsymbol{h} \boldsymbol{h a}^{-1}\right)$ & & & & & & & & \\
0 & 17,31 & 14,36 & 82,94 & 0,80 & 12,43 & 0,69 & 10,70 & 126,06 \\
150 & 16,92 & 13,94 & 82,33 & 0,82 & 12,00 & 0,71 & 11,01 & 122,07 \\
300 & 17,16 & 14,23 & 82,83 & 0,80 & 12,30 & 0,69 & 10,79 & 124,80 \\
450 & 17,35 & 14,46 & 83,33 & 0,78 & 12,46 & 0,67 & 10,99 & 126,17 \\
\hline Variedades & & & & & & & & \\
CTC 1 & $17,40 \mathrm{a}$ & $14,67 \mathrm{a}$ & $84,32 \mathrm{a}$ & $0,75 \mathrm{a}$ & $12,65 \mathrm{a}$ & $0,65 \mathrm{a}$ & $10,95 \mathrm{ab}$ & $127,72 \mathrm{a}$ \\
RB835054 & $17,41 \mathrm{a}$ & $14,58 \mathrm{a}$ & $83,72 \mathrm{a}$ & $0,77 \mathrm{a}$ & $12,63 \mathrm{a}$ & $0,67 \mathrm{~b}$ & $10,68 \mathrm{ab}$ & $127,78 \mathrm{a}$ \\
CTC 9001 & $17,30 \mathrm{a}$ & $14,23 \mathrm{a}$ & $82,26 \mathrm{ab}$ & $0,82 \mathrm{ab}$ & $12,18 \mathrm{ab}$ & $0,70 \mathrm{ab}$ & $11,35 \mathrm{a}$ & $123,79 \mathrm{ab}$ \\
RB965902 & $16,63 \mathrm{~b}$ & $13,50 \mathrm{~b}$ & $81,12 \mathrm{~b}$ & $0,86 \mathrm{~b}$ & $11,73 \mathrm{~b}$ & $0,75 \mathrm{~b}$ & $10,50 \mathrm{~b}$ & $119,81 \mathrm{~b}$ \\
\hline Teste $\boldsymbol{F}-$ Valores $\boldsymbol{d e} \boldsymbol{F}$ & & & & & & & \\
Variedades (V) & $5,96 * *$ & $11,42^{* *}$ & $4,71 * *$ & $4,67 * *$ & $9,79 * *$ & $4,75^{* *}$ & $3,09 *$ & $9,24 * *$ \\
Doses de $\mathrm{P}_{2} \mathrm{O}_{5}(\mathrm{P})$ & $1,66 \mathrm{~ns}$ & $2,07 \mathrm{~ns}$ & $0,38 \mathrm{~ns}$ & $0,39 \mathrm{~ns}$ & $2,25 \mathrm{~ns}$ & $0,41 \mathrm{~ns}$ & $0,54 \mathrm{~ns}$ & $2,33 \mathrm{~ns}$ \\
V x P & $1,92 \mathrm{~ns}$ & $3,22^{*}$ & $1,48 \mathrm{~ns}$ & $1,51 \mathrm{~ns}$ & $3,15 * *$ & $1,47 \mathrm{~ns}$ & $0,78 \mathrm{~ns}$ & $3,08 \mathrm{~ns}$ \\
R.L. & $0,31 \mathrm{~ns}$ & $0,72 \mathrm{~ns}$ & $0,31 \mathrm{~ns}$ & $0,29 \mathrm{~ns}$ & $0,36 \mathrm{~ns}$ & $0,52 \mathrm{~ns}$ & $0,49 \mathrm{~ns}$ & $0,30 \mathrm{~ns}$ \\
R.Q. & $3,62 \mathrm{~ns}$ & $4,30^{*}$ & $0,69 \mathrm{~ns}$ & $0,73 \mathrm{~ns}$ & $4,47 *$ & $0,63 \mathrm{~ns}$ & $0,07 \mathrm{~ns}$ & $4,60 *$ \\
\hline D.M.S. (V) & 0,58 & 0,59 & 2,51 & 0,09 & 0,52 & 0,08 & 0,79 & 4,72 \\
Média Geral & 17,19 & 14,24 & 82,85 & 0,80 & 12,30 & 0,69 & 10,87 & 124,77 \\
CV $(\%)$ & 3,57 & 4,42 & 3,21 & 11,38 & 4,52 & 11,59 & 7,71 & 4,01 \\
\hline
\end{tabular}

**Significativo a $1 \%$ pelo teste $\mathrm{F}$. ${ }^{*}$ Significativo a $5 \%$ pelo teste $\mathrm{F} . \mathrm{ns}=$ não significativo. D.M.S.= diferença mínima significativa. $\mathrm{CV}=$ coeficiente de variação. Médias seguidas de letra iguais, na coluna, não diferem entre si pelo teste de Tukey, em nível de 5\% de probabilidade.

$\mathrm{Na}$ Tabela 9 consta, o desdobramento da interação variedades $\mathrm{x}$ doses de fósforo para $\mathrm{o}$ teor de Pol\%caldo da cana-planta. A variedade RB835054, com o maior teor de Pol\%caldo, diferiu da variedade CTC 9001 na testemunha $\left(0 \mathrm{~kg} \mathrm{ha}^{-1}\right.$ de $\left.\mathrm{P}_{2} \mathrm{O}_{5}\right)$, enquanto que, na dose 150 e $300 \mathrm{~kg} \mathrm{ha}^{-1}$ de $\mathrm{P}_{2} \mathrm{O}_{5}$, o menor teor de Pol\%caldo foi da variedade RB965902. Constatou-se resposta para as doses de fósforo que se ajustou a função quadrática apenas para a variedade RB965902 ( $\left.y=0,000026 x^{2}-0,012168 x+14,2136\right)$ para a característica tecnológica Pol\%caldo.

Cultura Agronômica, Ilha Solteira, v.25, n.3, p.223-240, 2016 
Tabela 9. Desdobramento da interação variedades x doses de fósforo, da análise de variância referente ao Pol\%caldo da cana-de-açúcar (cana-planta). Aparecida do Taboado - MS, $2014 / 2015$.

\begin{tabular}{cccccccc}
\hline \multirow{2}{*}{ Variedades } & \multicolumn{3}{c}{ Doses de $\mathbf{P}_{2} \mathrm{O}_{5}\left(\mathrm{~kg} \mathrm{ha}^{-1}\right)$} & \multicolumn{3}{c}{ Valores de F } \\
\cline { 2 - 8 } & $\mathbf{0}$ & $\mathbf{1 5 0}$ & $\mathbf{3 0 0}$ & $\mathbf{4 5 0}$ & doses & R.L & R.Q. \\
\hline CTC 1 & $14,10 \mathrm{ab}$ & $14,65 \mathrm{a}$ & $14,95 \mathrm{a}$ & 14,97 & $1,65 \mathrm{~ns}$ & $4,24 *$ & $0,70 \mathrm{~ns}$ \\
RB835054 & $15,19 \mathrm{a}$ & $14,64 \mathrm{a}$ & $14,17 \mathrm{ab}$ & 14,33 & $2,04 \mathrm{~ns}$ & $4,72^{*}$ & $1,26 \mathrm{~ns}$ \\
CTC 9001 & $13,78 \mathrm{~b}$ & $13,90 \mathrm{a}$ & $14,50 \mathrm{a}$ & 14,73 & $2,14 \mathrm{~ns}$ & $6,02 *$ & $0,04 \mathrm{~ns}$ \\
RB965902 & $14,35 \mathrm{ab}$ & $12,56 \mathrm{~b}$ & $13,29 \mathrm{~b}$ & 13,81 & ${ }^{(1)} 5,89^{*}$ & $0,42 \mathrm{~ns}$ & $13,50^{* *}$ \\
\hline D.M.S. & 1,19 & 1,19 & 1,19 & 1,19 & - & - & -
\end{tabular}

Médias seguidas de letra iguais, na coluna, não diferem entre si pelo teste de Tukey, em nível de 5\% de probabilidade. D.M.S. $=$ diferença mínima significativa. ${ }^{(1)} \mathrm{y}=0,000026 \mathrm{x}^{2}-0,012168 \mathrm{x}+14,2136\left(\mathrm{R}^{2}=0,7875\right)$.

Na Tabela 10 consta, o desdobramento da interação variedades x doses de fósforo para a qualidade tecnológica PC (Pol\%cana) da cana-planta. A variedade RB835054, com o maior teor de PC, diferiu da variedade CTC 9001 na testemunha (0 kg ha $\left.{ }^{-1} \mathrm{de}_{2} \mathrm{O}_{5}\right)$, enquanto que, na dose 150 e $300 \mathrm{~kg} \mathrm{ha}^{-1}$ de $\mathrm{P}_{2} \mathrm{O}_{5}$, o menor teor de $\mathrm{PC}$ foi da variedade $\mathrm{RB} 965902$. Constatouse resposta para as doses de fósforo que se ajustou a função quadrática apenas para a variedade RB965902 $\left(y=0,000022 x^{2}-0,010569 x+12,360875\right)$ para a característica tecnológica Pol\%cana. Esses resultados foram semelhantes ao da variável Pol\%caldo (Tabela 9), já que para o cálculo do PC (Pol\%cana) levam-se em conta os valores de Pol\%caldo.

Tabela 10. Desdobramento da interação variedades x doses de fósforo, da análise de variância referente ao Pol\%cana da cana-de-açúcar (cana-planta). Aparecida do Taboado - MS, $2014 / 2015$.

\begin{tabular}{cccccccc}
\hline \multirow{2}{*}{ Variedades } & \multicolumn{3}{c}{ Doses de $\mathbf{P}_{2} \mathrm{O}_{5}\left(\mathrm{~kg} \mathrm{ha}^{-\mathbf{1}}\right)$} & \multicolumn{3}{c}{ Valores de F } \\
\cline { 2 - 8 } & $\mathbf{0}$ & $\mathbf{1 5 0}$ & $\mathbf{3 0 0}$ & $\mathbf{4 5 0}$ & doses & R.L & R.Q. \\
\hline CTC 1 & $12,21 \mathrm{ab}$ & $12,68 \mathrm{a}$ & $12,83 \mathrm{a}$ & 12,88 & $1,22 \mathrm{~ns}$ & $3,03 \mathrm{~ns}$ & $0,59 \mathrm{~ns}$ \\
RB835054 & $13,15 \mathrm{a}$ & $12,73 \mathrm{a}$ & $12,30 \mathrm{ab}$ & 12,35 & $2,00 \mathrm{~ns}$ & $5,16^{*}$ & $0,69 \mathrm{~ns}$ \\
CTC 9001 & $11,89 \mathrm{~b}$ & $11,72 \mathrm{ab}$ & $12,49 \mathrm{ab}$ & 12,64 & $2,62 \mathrm{~ns}$ & $5,89 *$ & $0,33 \mathrm{~ns}$ \\
RB965902 & $12,49 \mathrm{ab}$ & $10,90 \mathrm{~b}$ & $11,57 \mathrm{~b}$ & 11,97 & ${ }^{(1)} 5,84^{*}$ & $0,49 \mathrm{~ns}$ & $12,89 * *$ \\
\hline D.M.S. & 1,05 & 1,05 & 1,05 & 1,05 & - & - & - \\
\hline
\end{tabular}

Médias seguidas de letra iguais, na coluna, não diferem entre si pelo teste de Tukey, em nível de 5\% de probabilidade. D.M.S. $=$ diferença mínima significativa. ${ }^{(1)} \mathrm{y}=0,000022 \mathrm{x}^{2}-0,010569 \mathrm{x}+12,360875\left(\mathrm{R}^{2}=\right.$ 0,7636).

\section{CONCLUSÃO}

A variedade RB965902 apresentou os menores valores das características que compõem a qualidade da matéria-prima.

As doses de fósforo aplicadas no sulco de plantio da cana-de-açúcar, proporcionam aumento linear no índice de área foliar, nos teores foliares de $\mathrm{N}, \mathrm{P}$ e $\mathrm{Mg}$, porém não influenciam as características agronômicas, produtividade de colmos e agroindustrial e qualidade tecnológica.

Cultura Agronômica, Ilha Solteira, v.25, n.3, p.223-240, 2016 
Ocorre influencia da interação variedades x doses de $\mathrm{P}$ no teor de $\mathrm{P}$ e $\mathrm{Mg}$ foliar e Pol\%caldo e Pol\%cana (PC).

\section{REFERÊNCIAS BIBLIOGRÁFICAS}

BARBIERI, V. Condicionamento climático da produtividade potencial da cana-deaçúcar (Saccharum spp.): um modelo matemático-fisiológico de estimativa. Piracicaba, 1993. 142 f. Tese (Doutorado em Agronomia) - Escola Superior de Agricultura "Luiz de Queiroz", Universidade de São Paulo, Piracicaba, 1993.

CAIONE, G.; TEIXEIRA, M. T. R.; LANGE, A.; SILVA, A. F.; FERNANDES, F. M. Modos de aplicação e doses de fósforo em cana-de-açúcar forrageira cultivada em Latossolo Vermelho Amarelo. Revista de Ciências Agro-ambientais, Alta Floresta, v. 9, n. 1, p.1-11, 2011.

CASTRO, P. R. C.; CHRISTOFFOLETI, P. J. Fisiologia da cana-de-açúcar. In: MENDONÇA, A. F. Cigarrinhas da cana-de-açúcar: Controle biológico. 1. ed. Maceió: Insecta, 2005. cap. 3, p. 3-48.

CONSELHO DOS PRODUTORES DE CANA-DE-AÇÚCAR, AÇÚCAR E ÁLCOOL DO ESTADO DE SÃO PAULO - CONSECANA. Manual de Instruções. 4. ed. Piracicaba: Opinião, 2003. 116 p.

COSTA, D. B.; ANDRADE, P. K. B.; SILVA, S. A. M.; SIMÕES NETO, D. E.; FREIRE, F. J.; OLIVEIRA, E. C. A. Adubação fosfatada em cana planta e soca em Argissolos do nordeste de diferentes texturas. Revista Caatinga, Mossoró, v. 27, n. 4, p.47-56, 2014.

DAROS, E.; ZAMBON, J. L. C.; WEBER, H.; IDO, O. T.; GRACIANO, P. A. Efeito da densidade de plantio em duas variedades de cana-de-açúcar. In: CONGRESSO NACIONAL DA SOCIEDADE DOS TÉCNICOS AÇUCAREIROS E ALCOOLEIROS DO BRASIL STAB, 7., 1999, Londrina. Anais... Londrina: Sociedade dos Técnicos Açucareiros e Alcooleiros do Brasil, 1999, p. 137-140.

DEMATTÊ, J. A. Levantamento semi-detalhado de solos relacionados aos grupos de manejo em ambientes de produção das terras da Alcoolvale. Piracicaba: UNIALCOOL S/A, 2007. CD-ROM.

DILLEWIJN, C. Van. Botany of sugarcane. Walthan: Chronica Botanica, 1952. 371 p.

FERREIRA, D. F. Análises estatísticas por meio do Sisvar para Windows versão 4.0. In: REUNIÃO ANUAL DA REGIÃO BRASILEIRA DA SOCIEDADE INTERNACIONAL DE BIOMETRIA, 45., 2000, São Carlos. Anais... São Carlos: UFSCar, 2000. p. 255-258.

GHELLER, A. C. A.; MENEZES, L. L.; MATSUOKA, S.; MASUDA, Y.; HOFFMANN, H. P.; ARIZONO, H.; GARCIA, A. A. F. Manual de método alternativo para medição da produção de cana-de-açúcar. Araras: UFSCar - CCA - DBV, 1999. 7p.

HERMANN, E. R.; CÂMARA, G. M. S. Um método simples para estimar a área foliar de cana-de-açúcar. STAB, Piracicaba, v.17, n. 5, p.32-34, 1999.

Cultura Agronômica, Ilha Solteira, v.25, n.3, p.223-240, 2016 
KORNDORFER, G. H.; FARIA, R. J.; MARTINS, M. Efeito do fósforo na produção da canade-ano e cana-soca em solo de cerrado. Pesquisa Agropecuária Brasileira, Brasília, v. 33, n. 10, p. 1667-1673, 1998.

MACHADO, E. C.; PEREIRA, A. R.; PAES CAMARGO, M. B.; FAHL, J. I. Relações radiométricas de uma cultura de cana-de-açúcar. Bragantia, Campinas, v. 44, n. 1, p.229$238,1985$.

MALAVOlTA, E.; VITTI, G. C.; OLIVEIRA, S. A. Avaliação do estado nutricional das plantas: princípios e aplicações. 2. ed. Piracicaba: Associação Brasileira para Pesquisa da Potassa e do Fosfato, 1997. 319p.

MEYER, J. H.; WOOD, R. A. The effects of soil fertility and nutrition on sugarcane quality: a review. South African Sugar Technologists Association, Mount Edgecombe, v. 75, n. 1, p.242-245, 2001.

MODA, L. R. Fontes e doses de fósforo na presença e ausência de composto orgânico no estado nutricional e na produtividade da cana-de-açúcar. 2015. 138 f. Tese (Doutorado em Agronomia - Ciência do solo) - Universidade Estadual Paulista, Faculdade de Ciências Agrárias e Veterinárias, Jaboticabal, 2015.

MOURA, A. B. Produtividade agrícola e industrial da cana-de-açúcar sob diferentes fontes e doses de fósforo. 2014. 76 f. Dissertação (Mestrado em Produção Vegetal) - Centro de Ciências Agrárias, Universidade Federal de Alagoas, Rio Largo, 2014.

OLIVEIRA, R. A.; DAROS, E.; ZAMBON, J. L. C.; WEBER, H.; IDO, O. T.; BESPALHOK-FILHO, J. C.; ZUFFELATO-RIBAS, K. C.; SILVA, D. K. T. Área foliar em três cultivares de cana-de-açúcar e sua correlação com a produção de biomassa. Pesquisa Agropecuária Tropical, Goiânia, v. 37, n. 2, p.71-76, 2007.

PEREIRA, J. R.; FARIA, C. M. B.; MORGADO, L. B. Efeito de níveis e do resíduo de fósforo sobre a produtividade da cana-de-açúcar em vertissolo. Pesquisa Agropecuária Brasileira, Brasília, v. 30, n. 1, p.43-48, 1995.

PRADO, A. P. A. Perfilhamento e produção da cana-de-açúcar (Saccharum spp.) em função da densidade de plantio. 1988. 69 p. Dissertação (Mestrado em Fitotecnia) - Escola Superior de Agricultura "Luiz de Queiroz" - Universidade de São Paulo, Piracicaba, 1988.

RAIJ, B. van; ANDRADE, J. C.; CANTARELlA, H.; QUAGGIO, J. A. (Ed.). Análise química para avaliação da fertilidade de solos tropicais. Campinas: Instituto Agronômico, 2001. $285 \mathrm{p}$.

RAIJ, B. van; CANTARELLA, H. Outras culturas industrais. In: RAIJ, B. van; CANTARELlA, H.; QUAGGIO, J. A.; FURLANI, A. M. C. Recomendações de calagem e adubação para o Estado de São Paulo. 2.ed. Campinas: IAC, 1997. p.233-239 (Boletim técnico, 100).

SANTOS, D. H.; SILVA, M. A.; TIRITAN, C. S.; FOLONI, J. S. S.; ECHER, F. R. Qualidade tecnológica da cana-de-açúcar sob adubação com torta de filtro enriquecida com fosfato

Cultura Agronômica, Ilha Solteira, v.25, n.3, p.223-240, 2016 
solúvel. Revista Brasileira de Engenharia Agrícola e Ambiental, Campina Grande, v. 15, n. 5, p.443-449, 2011.

SILVA, M. A.; LANDELL, M. G. A.; CAMPANA, M. P.; XAVIER, M. A. Produtividade de mudas sob diferentes densidades de plantio, em viveiro oriundo de cultura de meristema. In: CONGRESSO NACIONAL DA SOCIEDADE DOSTÉCNICOS AÇUCAREIROS E ALCOOLEIROS DO BRASIL - STAB, 8., 2002, Recife. Anais... Recife: Sociedade dos Técnicos Açucareiros e Alcooleiros do Brasil, 2002., p.538-543.

SIMÕES NETO, D. E.; OLIVEIRA, A. C.; ROCHA, A. T.; FREIRE, F. J.; FREIRE, M. B. G. S.; NASCIMENTO, C. W. A. Características agroindustriais da cana-de-açúcar em função da adubação fosfatada, em solos de Pernambuco. Revista Brasileira de Engenharia Agrícola e Ambiental, Campina Grande, v. 16, n. 4, p.347-354, 2012.

SOUZA, E. P. Desempenho de variedades de cana-de-açúcar em doses de adubação fosfatada corretiva em solo originalmente coberto por vegetação de cerrado. $2007.49 \mathrm{f}$. Trabalho de Graduação (Agronomia), Universidade Estadual Paulista, Faculdade de Engenharia de Ilha Solteira, Ilha solteira, 2007.

TAIZ, L.; ZEIGER, E. Fisiologia vegetal. 3. ed. Porto Alegre: Artmed, 2004. 526 p.

TEIXEIRA, E. B. Adubação corretiva de fósforo sobre o desempenho de variedades de cana-de-açúcar cultivadas em ambiente restritivo de cerrado. 2014. 75 f. Dissertação (Mestrado em Agronomia - Especialidade Sistemas de Produção), Universidade Estadual Paulista, Faculdade de Engenharia de Ilha Solteira, Ilha Solteira, 2014. 